\title{
A Systematic Review of the Peer-Reviewed Literature on Self-Blame, Guilt, and Shame
}

OMEGA-Journal of Death and Dying

$0(0)|-3|$

(C) The Author(s) 2015

Reprints and permissions: sagepub.com/journalsPermissions.nav DOI: 10.1 I77/00302228I5572604 ome.sagepub.com

@SAGE

\section{Catherine Duncan' and Joanne Cacciatore ${ }^{2}$}

\begin{abstract}
This is the first systematic review of the evidence on the prevalence of self-blame, guilt, and shame in bereaved parents. A search of PsychINFO, MEDLINE, Embase, CINAHL, PubMed, and Science Direct resulted in 18 studies for the period 1975 to 2013 which the authors have appraised. Self-blame, guilt, and shame are common in bereaved parents, albeit to varying degrees, with differential relationships to sex, and diminishing over time. There is some evidence that guilt and shame predict more intense grief reactions and that self-blame predicts posttraumatic symptomology, anxiety, and depression in bereaved parents. Heterogeneity of the studies and numerous methodological concerns limit the synthesis and strength of the evidence and the generalizability of the findings. Self-blame, guilt, and shame are commonly experienced by bereaved parents. Awareness of these affective states may assist clinicians in the identification of bereaved parents who are at a higher risk of developing adverse psychological outcomes. Overall, self-blame, guilt, and shame have received very little attention in the bereavement research, leaving many unanswered questions. Implications for practice and recommendations for future research are discussed.
\end{abstract}

\section{Keywords}

parental bereavement, death of a child, shame, guilt, self-blame, grief

'School of Social Work, University of Calgary, Alberta, Canada

${ }^{2}$ School of Social Work, Arizona State University, Tempe, AZ, USA

Corresponding Author:

Catherine Duncan, PO Box 306, Vashon, WA, 98070, USA.

Email: cath@rememberingforgood.com 
Self-blame, guilt, and shame are common in bereavement and may hinder the healthy progression of mourning (Buckle \& Fleming, 2011; Humphrey, 2009; Rando, 1986). Guilt is also included as a psychological outcome in many commonly used grief scales (e.g., Bereavement Experience Questionnaire [BEQ], Demi \& Schroeder, 1987; Grief Evaluation Measure [GEM], Jordan, Baker, Matteis, Rosenthal, \& Ware, 2005; The Perinatal Grief Scale [PGS], Potvin, Lasker, \& Toedter, 1989; Inventory of Complicated Grief [ICG], Prigerson et al., 1995; Grief Experience Inventory [GEI], Sanders, Mauger, \& Strong, 1985; The Perinatal Bereavement Scale [PBS], Theut et al., 1989). However, self-blame, guilt, and shame have received relatively little attention in parental bereavement research. Reviews of guilt and shame in bereavement are either not current or comprehensive, narrative in style and therefore more susceptible to researcher bias or focused on various types of bereavement rather than parental bereavement specifically (Buckle \& Fleming, 2011; Humphrey, 2009; Rando, 1986). Miles and Demi (1986) have proposed the only current theory of guilt in bereaved parents. While clinicians acknowledge that self-blame, guilt, and shame often hinder the progression of normal grieving, there are currently no robust, empirically tested theories of self-blame, guilt, and shame in bereaved parents to guide either diagnoses or interventions.

This is the first systematic review of the literature on self-blame, guilt, and shame in bereaved parents characterized by a specific research question, inclusion and exclusion criteria, an explicit search strategy, systematic data extraction procedure, coding and analysis of the studies, methodological appraisal, and a synthesis of the available evidence text. These characteristics reduce the likelihood of reviewer bias or selective citation and provide readers with the information necessary to appraise both the included studies and the systematic review itself (Mulrow, 1994; Pai et al., 2004).

\section{Defining Self-Blame, Guilt, and Shame}

Both guilt and shame are self-conscious emotions involving self-blame (Tangney $\&$ Salovey, 1999) and, because they are intimately related, they are more difficult to observe as separate phenomena (Blum, 2008; Kubany \& Watson, 2003; Silfver, 2007). Guilt and shame are therefore often conflated in research and practice. Yet, conceptually, they are quite different phenomena. Early theories of guilt and shame focused on biological or intrapsychic processes. Shame was understood through the lens of libidinal conflicts and Erikson's theories of identity development through the life cycle. Lewis (1971), however, hypothesized that shame was related to attachment distress. Recent theories of guilt and shame have acknowledged the interpersonal cadence of both guilt and shame (Baumeister, Stillwell, \& Heatherton, 1994; Broucek, 1991; Scheff, 2000, 2012; Tangney \& Salovey, 1999). Shame and guilt can be experienced in both public and private circumstances, and it is an individual's interpretation of the situation 
that determines whether guilt or shame (or both) develop (Tangney \& Salovey, 1999).

Experientially, shame is typically associated with a sense of exposure along with a lack of trust, feelings of worthlessness, powerlessness, and a desire to hide. Guilt is associated with feelings of tension, regret, and remorse. In the case of shame, the ego is concerned with self-evaluation, but in the case of guilt, one is more other-focused, preoccupied with assessing the impact of actions on others. Shame motivates avoidance or projection of anger, while guilt often motivates constructive engagement in relationships and reparative action (Broucek, 1991; Tangney \& Salovey, 1999). While heterogeneity is still evident in the definitions of guilt and shame, many researchers agree that guilt is a negative evaluation of behavior, and shame is a negative evaluation of the global self (Brown, 2006; Tangney, Miller, Flicker, \& Barlow, 1996; Tangney, Stuewig, \& Mashek, 2007). Shame, but not guilt, may threaten the attachment system and general sense of belonging, and this is, perhaps, its essential source of pain (Broucek, 1991; Brown, 2006).

Most often, guilt is conceptualized as adaptive, and shame is conceptualized as maladaptive. Shame is strongly related to a wide range of problems including avoidance of interpersonal problems and poorer interpersonal problem-solving capacity, projection of anger toward others, depression, anxiety, eating disorders, body image difficulties, substance abuse, posttraumatic stress disorder, and suicide (Behrendt \& Ben-Ari, 2012; Dickerson, Gruenewal, \& Kemeny, 2004; Fergus, Valentiner, McGrath, \& Jencius, 2010; Goss \& Allan, 2009; Grabe, Hyde, \& Lindberg, 2007; Hoglund \& Nicholas, 1995; Kim, Thibodeau, \& Jorgensen, 2011; Leskela, Dieperink, \& Thuras, 2002; Lester, 1998; Street \& Arias, 2001; Tangney \& Dearing, 2002; Wiginton, Rhea, \& Oomen, 2004). Guilt, on the other hand, is highly correlated to empathy and prosocial behavior (Behrendt \& Ben-Ari, 2012; Brown, 2006, Tangney \& Dearing, 2002; Tangney et al., 1996; Tangney \& Salovey, 1999; Tangney et al., 2007). It is the behavioral focus of guilt which enables individuals to feel capable of making amends by changing their behavior, while the global negative self-evaluation involved in shame may make the prospect of change or remediation seem impossible (Tangney \& Salovey, 1999).

O'Connor, Berry, Weiss, Bush, and Sampson (1997) disagree with the view that guilt is always adaptive, and propose that guilt can also become excessive. Studies have found relationships between guilt and depression, eating disorders, anxiety, hostility, low self-esteem, and suicide (Alexander, Brewin, Vearnals, Wolff, \& Leff, 1999; Bryan, Ray-Sannerud, Morrow, \& Etienne, 2013; Ghatavi, Nicolson, MacDonald, Osher, \& Levitt, 2002; Harder, Cutler, \& Rockart, 1992; Kim et al., 2011; Rortveit, Astrom, \& Severinsson, 2010). In addition, feelings of worthlessness and excessive guilt are listed as part of the criteria for diagnosing major depressive disorder (MDD) in the Diagnostic and Statistical Manual of Mental Disorders, 4th Edition, Text Revision (American Psychiatric 
Association, 2000). While guilt and shame have been conceptualized as emotions or affective states, self-blame is conceptualized as a cognitive appraisal or attribution:

Behavioral self-blame is control related, involves attributions to a modifiable source (one's behavior), and is associated with a belief in the future avoidability of a negative outcome. Characterological self-blame is esteem related, involves attributions to a relatively non-modifiable source (one's character), and is associated with a belief in personal deservingness for past negative outcomes. (JanoffBulman, 1979, p. 1798)

Janoff-Bulman conceptualizes behavioral self-blame as adaptive and characterological self-blame as maladaptive and argues that the primary distinguishing feature is the perceived controllability of factors that are subject to selfevaluation. Self-blame was included in this review, alongside guilt and shame, because self-blame attributions are evident in guilt and shame (Kubany \& Watson, 2003). However, we have treated self-blame as a separate construct from guilt and shame because most of the literature conceptualizes self-blame differently, and behavioral self-blame does not have consistent relationships with guilt (Lutwak, Panish, \& Ferrari, 2003; Tangney, Wagner, \& Gramzow, 1992; Tilghman-Osborne, Felton, \& Ciesla, 2008; Tracy \& Robbins, 2006). Findings in respect of the relationships between characterological and behavioral self-blame and depression are inconsistent, but there is some indication that characterological self-blame is either concomitant or a consequence of depressive states rather than a cause (Downey, Silver, \& Wortman, 1990; Janoff-Bulman, 1979; Peterson, Schwartz, \& Seligman, 1981; Tilghman-Osborne et al., 2008; Weinberg, 1995).

\section{Methods}

This systematic review focused on peer-reviewed literature of bereaved parents from January 1975 until November 2013. We sought evidence on the prevalence of self-blame, guilt, and shame in bereaved parents, as well as the relationships between self-blame, guilt, and shame and any measures of psychological adaptation after loss.

\section{Search Strategy}

During February 2013, the following electronic journal databases were searched: PsycINFO, MEDLINE, Embase, CINAHL, PubMed, and Science Direct. The following key words were used in the search: bereaved parents, child death, perinatal death, neonatal death, stillbirth, sudden infant death, shame, guilt, attributions, self-blame, self-conscious emotion, and self-criticism. 
Furthermore, all reference lists in relevant studies were manually searched. The search was repeated in November 2013, and no new studies met the review criteria.

\section{Study Eligibility}

Studies were included in this systematic review if they met all of the following criteria:

1. The study sample consisted of male and/or female bereaved parents over the age of 18. Studies that focused solely on samples who had experienced early miscarriage or elective abortion were excluded because these groups may not necessarily consider themselves as bereaved parents, and there is some evidence that their grief reactions may differ significantly (Broen, Moum, Bodtker, \& Ekeberg, 2004; Reagan, 2003). However, few studies focusing on stillbirth and early neonatal death had excluded miscarriage and/or late termination for fetal anomaly from their samples and these studies were included.

2. The study explicitly sought to understand self-blame and/or guilt and/or shame in the experience of bereaved parents. We did not restrict our criteria to any particular definition or operationalization of self-blame, guilt, or shame. Exploratory studies that did not expressly seek to understand selfblame, guilt, or shame yet reported them in their results were excluded because doing so would bias the review by not also including all exploratory studies that did not find evidence of self-blame, guilt, or shame (e.g., Adolfsson, Larsson, Wijma, \& Bertero, 2004; Clyman, Green, Rowe, Mikkelsen, \& Ataide, 1980; DeFrain, Martens, Stork, \& Stork, 1990; DeFrain, Millspaugh, \& Xie, 1996; Frost \& Condon, 1996; Hsu, Tseng, Banks, \& Kuo, 2004; Mandell, McAnulty, \& Reece, 1980; Robinson, 2011; Samuelsson, Radestad, \& Segesten, 2001; Smialek, 1978; Taub, 1996).

3. The study was in English.

4. The study clearly articulated their research design, methods, and outcomes, so that we would be able to appraise the methodology.

5. The study was published in or after January 1975 until November 2013.

6 . The study has been published in a peer-reviewed journal.

Our initial combined search generated 1,321 results. After reviewing the study abstracts, 1,300 studies that did not meet the inclusion criteria were eliminated. The remaining 21 studies were checked for duplicates, which were removed, leaving 17 studies for which we retrieved the full text. After a manual search of references, two studies were added. A third study in press was also included for a total of 20 studies. Both authors independently reviewed these 20 studies and agreed on the inclusion of 17 studies but disagreed on the inclusion of the 
18th study. Disagreement was resolved through discussion and resulted in the inclusion of the study. Two studies were excluded because one study did not clearly articulate their methodology (Hasui \& Kitamaru, 2004), and one study assessed a variety of negative affects and cognitive schemata but did not report the results for self-blame, guilt, or shame specifically (Jind, Elklit, \& Christiansen, 2010).

\section{Data Extraction}

The remaining 18 studies were summarized according to their study populations, sampling techniques, recruitment methods (Tables 12 ), study designs, instruments, and major findings (Tables 34 ). We then completed appraisals of the studies and the strength of their evidence. Owing to the heterogeneity of the selected studies, we did not conduct a meta-analysis of the data.

\section{Results}

Eighteen studies were included in the review. Fifteen studies were quantitative, two studies were qualitative, and one study used a mixed method approach.

\section{Appraisal of Sampling Techniques}

Table 1 summarizes the qualitative studies. In Miles and Demi's (1983) study, participants were recruited from a seminar titled "coping with guilt," while the participants in De Tychey and Dollander's (2007) study were recruited through the researchers' psychotherapy practice. Neither of the studies included a discussion about how their recruitment methods may have impacted on their data collection or interpretation. In addition, demographic data, details pertinent to understanding both context and meaning making in respect of guilt in bereavement, were not collected by Miles and Demi. Both qualitative studies included bereaved parents with different types of loss and time since loss but did not discuss the relevance of these variables in their interpretation. Finally, all participants in De Tychey and Dollanders' study had been previously diagnosed with MDD. Guilt is one of the criteria for the diagnosis of MDD, a potential confound.

Table 2 summarizes the quantitative and mixed method studies. Twelve studies included both bereaved mothers and bereaved fathers, but only six of these studies completed a gender analysis of their results, finding significant differences between men and women. Only seven studies limited their sample to just one type of loss, yet the nature of a child's death may be very pertinent to experiences of self-blame, guilt, and shame (Broen et al., 2004). Only three studies compared the results for their bereaved parent participants with a nonbereaved control group or normed bereavement group. Self-blame, guilt, and shame seem to 


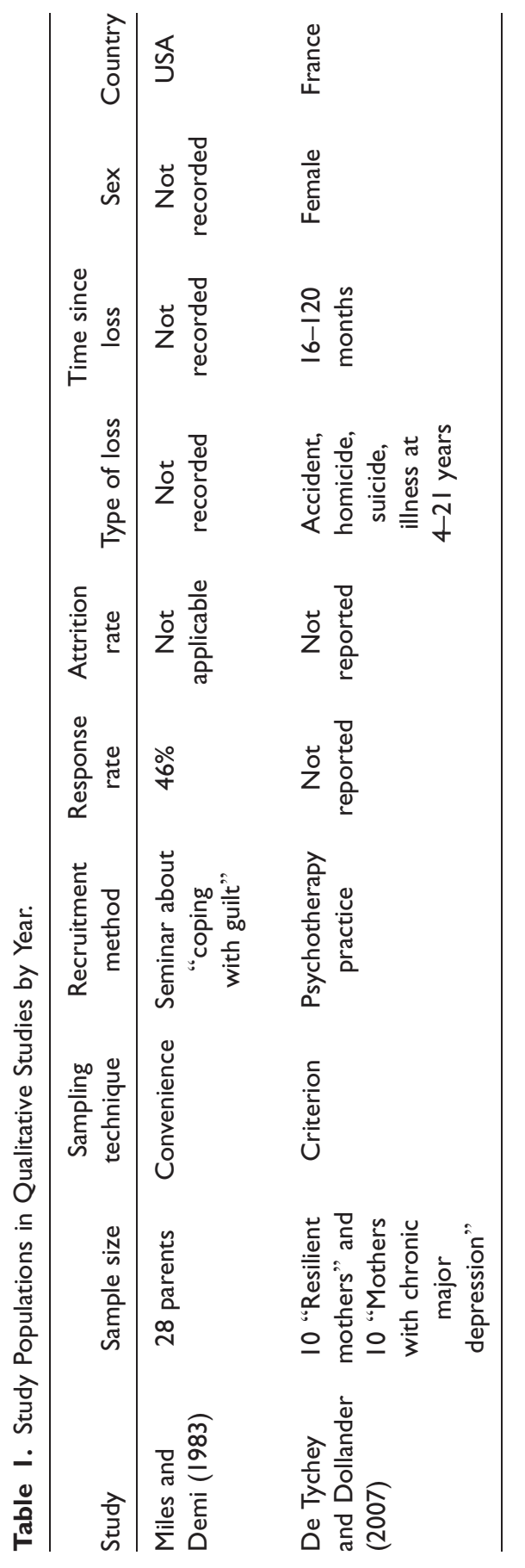




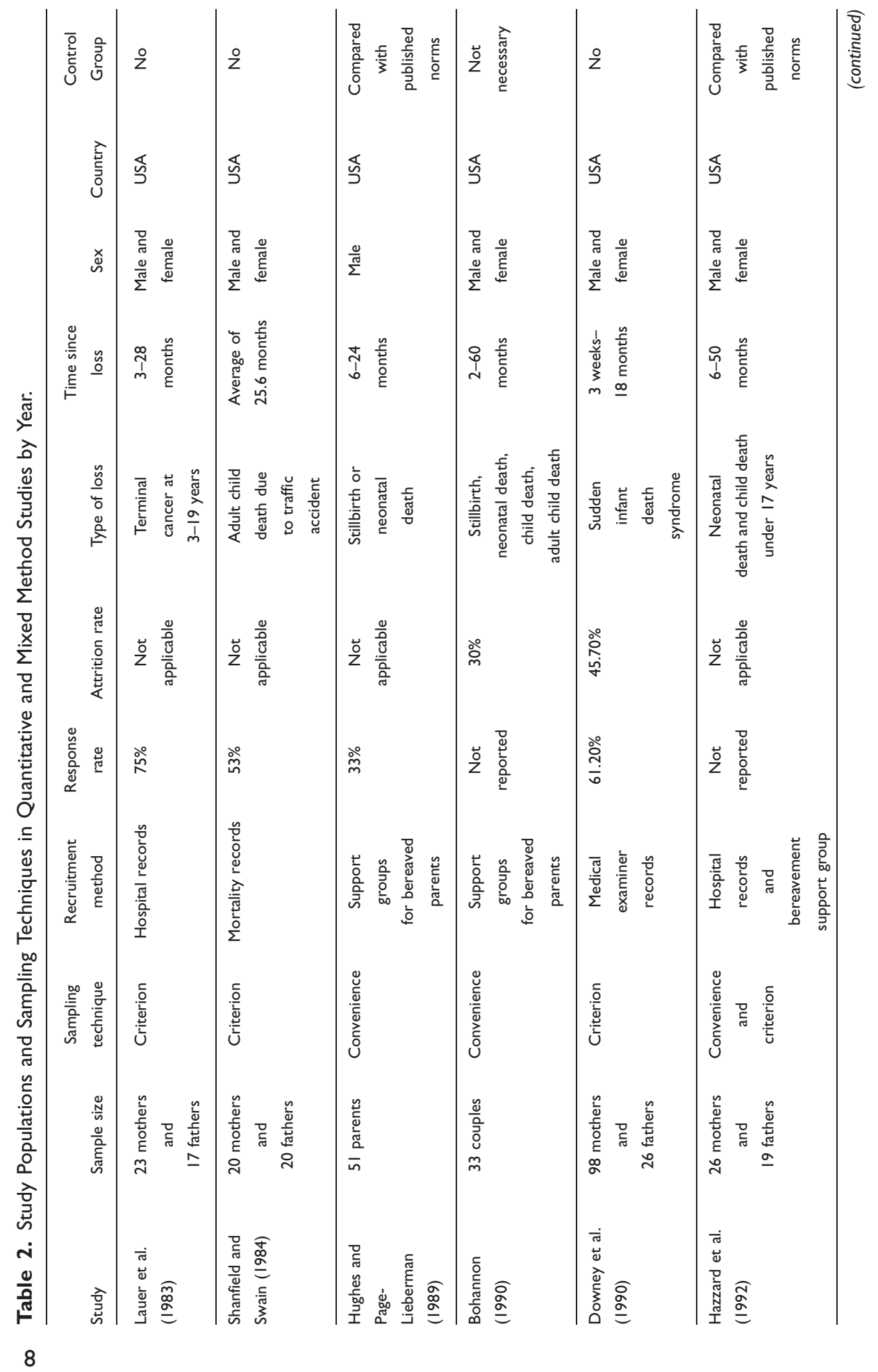




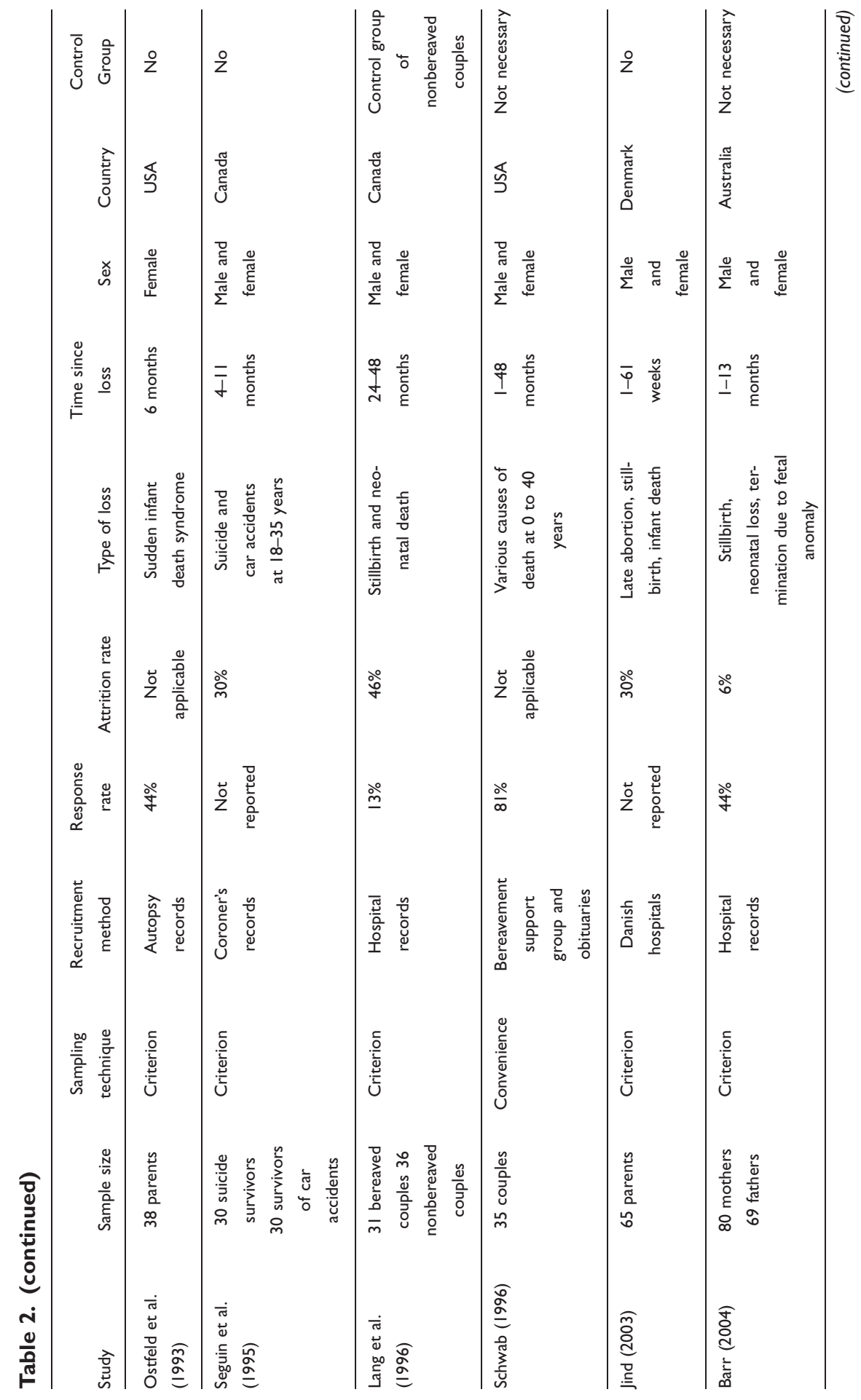




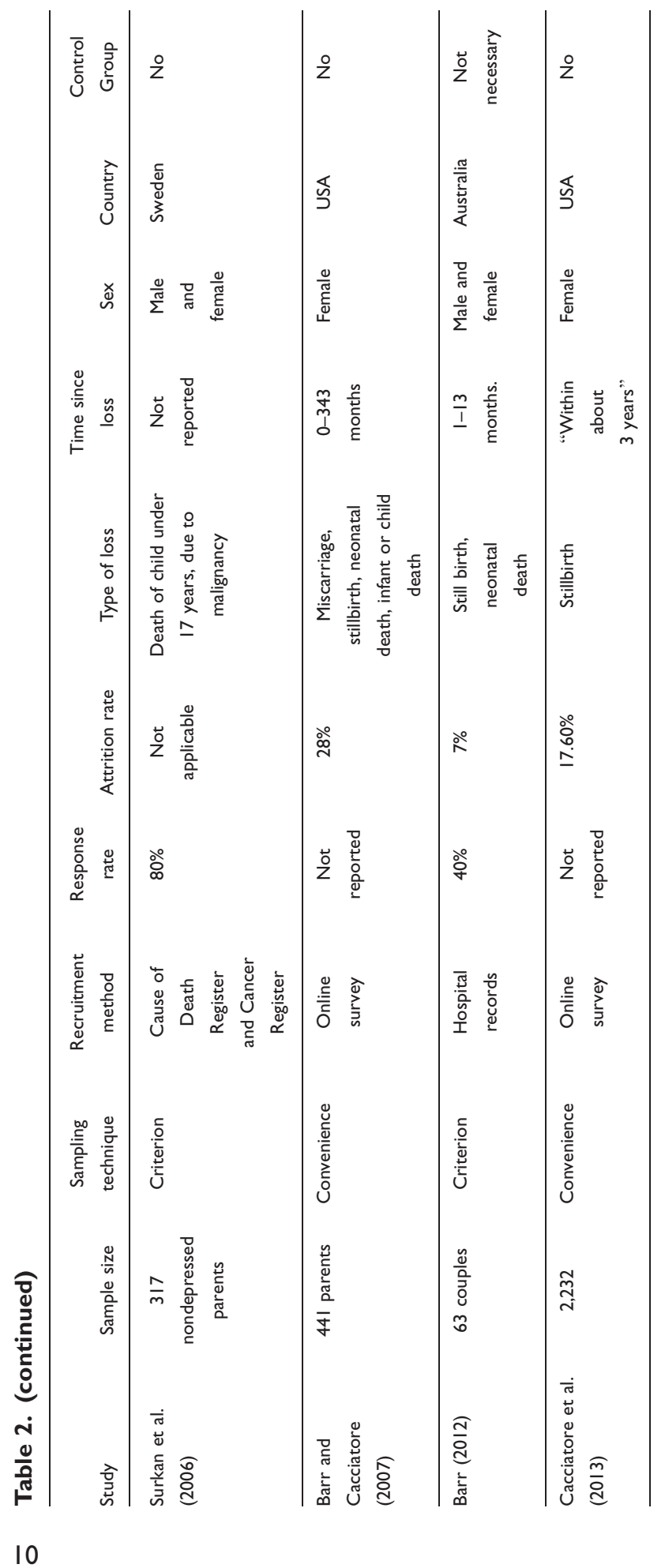




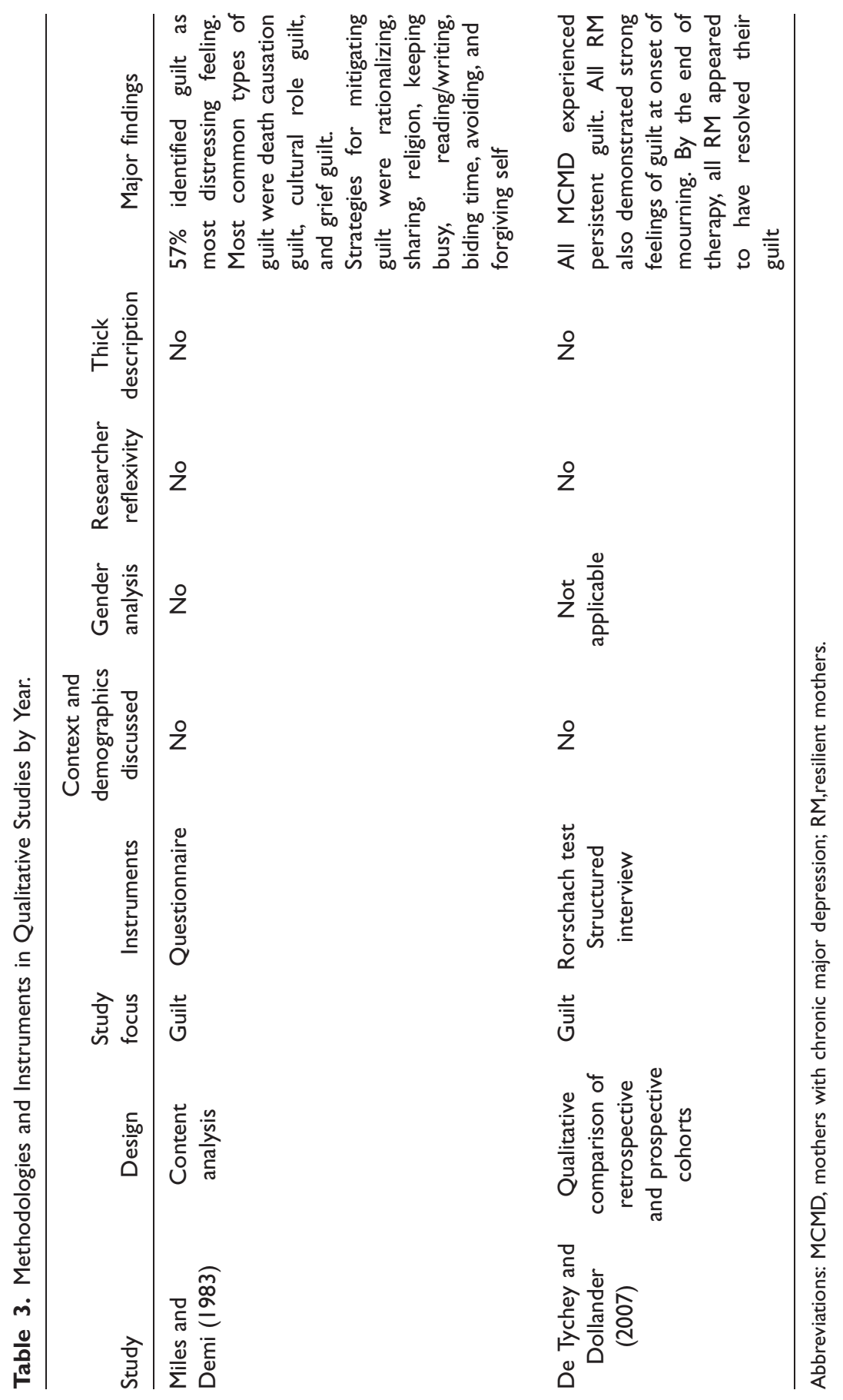


diminish over time, but only six studies included an analysis of the effects of time since loss (Barr, 2004, 2012; Downey et al., 1990; Jind, 2003; Ostfeld, Ryan, Hiatt, \& Heygi, 1993; Seguin, Lesage, \& Kiely, 1995). None of the quantitative studies reported power calculations for sample sizes, and three studies had very small samples considering the multiple variables in the analyses (Hazzard, Weston, \& Gutterres, 1992; Lauer, Mulhern, Wallskog, \& Camitta, 1983; Shanfield \& Swain, 1984).

Ten of the quantitative studies were conducted in the United States. Only six studies reported the ethnicity of their participants, and five of these had predominantly White participants (Barr, 2004, 2012; Barr \& Cacciatore, 2007; Cacciatore, Froen, \& Killian, in press; Jind, 2003). Four studies reported that their samples were limited to English-speaking participants (Barr, 2004, 2012; Barr \& Cacciatore, 2007; Downey et al., 1990), and nine other studies conducted in the United States were probably also with English-speaking populations, though they did not report on the language of their sample. Only four studies reported the socioeconomic status of their participants (Downey et al., 1990; Hazzard et al., 1992; Hughes \& Page-Lieberman, 1989; Seguin et al., 1995). Ten studies reported the education levels of their participants, and all except for one, had highly educated samples. Guilt and shame are sociocultural phenomena (Brown, 2006; Scheff, 2012), but most of the studies included in this review did not discuss the relationships between gender, socioeconomic, and cultural factors and self-blame, guilt, and shame.

All studies were subject to potential participant biases that may be particularly relevant to social emotions like guilt and shame. The behavioral inclination in shame is to cover up or hide (Tangney \& Salovey, 1999), so it is possible that participants either experienced less shame or had developed more shame resilience than the nonresponders. Guilt, on the other hand, is expected to positively predict prosocial behavior that may increase a person's willingness to participate in a research study. Only two of the studies reported differences between the characteristics of responders and nonresponders (Downey et al., 1990; Lang, Gottlieb, \& Amsel, 1996).

\section{Appraisal of Methodology and Measures}

Table 3 summarizes the qualitative studies. The qualitative approach is best suited for exploring subjective meanings and providing a "thick description" of actions, interactions, and social processes in local contexts (Popay, Rogers, \& Williams, 1998). Miles and Demi (1983) and De Tychey and Dollander (2007) did not provide a thick description of their results, nor did they discuss context or the researcher-participant relationship. These omissions reduce the transferability of their findings (Popay et al., 1998, p. 347). Miles and Demi's preestablished system of codes may have made the findings more susceptible to interpretation bias. De Tychey and Dollander appear to have begun with a quantitative 
approach and switched to a qualitative content analysis when the researchers realized the data lacked statistical power. It is also unclear how De Tychey and Dollander transformed their data, and the study utilized the Rorschach test, a controversial assessment instrument (Garb, Wood, Lilienfeld, \& Nezworski, 2005; Garb, Wood, Nezworski, Grove, \& Stejskal, 2001; Hiller, Rosenthal, Bornstein, Berry, \& Brunell-Neuleib, 1999; Parker, Hanson, \& Hunsley, 1988).

Table 4 summarizes the mixed method study and quantitative studies. In Hughes and Page-Lieberman's (1989) study, guilt is assessed retrospectively and may be skewed by memory bias. Findings concluded that $57 \%$ of the participants expressed guilt, but it is not clear how the results of the GEI and structured interview were combined to arrive at that figure.

A wide range of instruments was used in the quantitative studies. Twelve of the quantitative studies used instruments not tested for validity for measuring selfblame, guilt, or shame. The GEI (Sanders et al., 1985) and BEQ (Demi \& Schroeder, 1987) include items for guilt, while the Grief Experience Questionnaire (GEQ; Barrett \& Scott, 1990) includes items for shame. The GEI has been validated (Schwab, 1996), but validation of the GEQ and BEQ has not been reported. However, these scales were all developed for measuring grief rather than guilt or shame specifically (Tomita \& Kitamura, 2002), and the Cronbach's alpha coefficient for GEI guilt is .57 (Bohannon, 1990). Only three studies used instruments specifically operationalized for measuring guilt and shame (Barr, 2004, 2012; Barr \& Cacciatore, 2007). The Personal Feelings Questionnaire (PFQ-2; Harder \& Lewis, 1987) measures chronic shame and guilt, while the Test of Self-Conscious Affect (TOSCA-2; Tangney, Wagner, \& Gramzow, 1989) measures situational shame and guilt (Barr, 2004, 2012). The Interpersonal Guilt Questionnaire (IGQ; O'Connor et al., 1997) measures maladaptive guilt.

The TOSCA has been critiqued for presuming that the way that people respond to fictitious scenarios reflects how they respond in real life. The PFQ and TOSCA Shame Scales may be less valid for bereaved parents because domains of shame such as stigma, unwanted identity, and gender role stress, which may be especially relevant in this population, are not addressed. Concerns with the PFQ-2 Guilt subscale specifically include strong correlations with the PFQ-2 Shame subscale (Andrews, 1998), short test-retest time frames (Andrews, 1998; Rizvi, 2010), and the presumption that participants have a sophisticated vocabulary and can differentiate between the various adjectives listed. It also does not assess how long the respondents have been feeling guilt and shame. The TOSCA Guilt subscale has been criticized because of low internal consistency, poor correlation with other guilt measures, potential confounding of guilt with moral standards, and that it measures only adaptive guilt and not maladaptive forms of guilt (Andrews, 1998; Barr, 2012; Luyten, Fontaine, \& Corveleyn, 2002; Rizvi, 2010). Despite these problems, the shame subscales for the TOSCA-2 and PFQ-2 may be more sensitized instruments for measuring shame than those used in the other quantitative studies. 


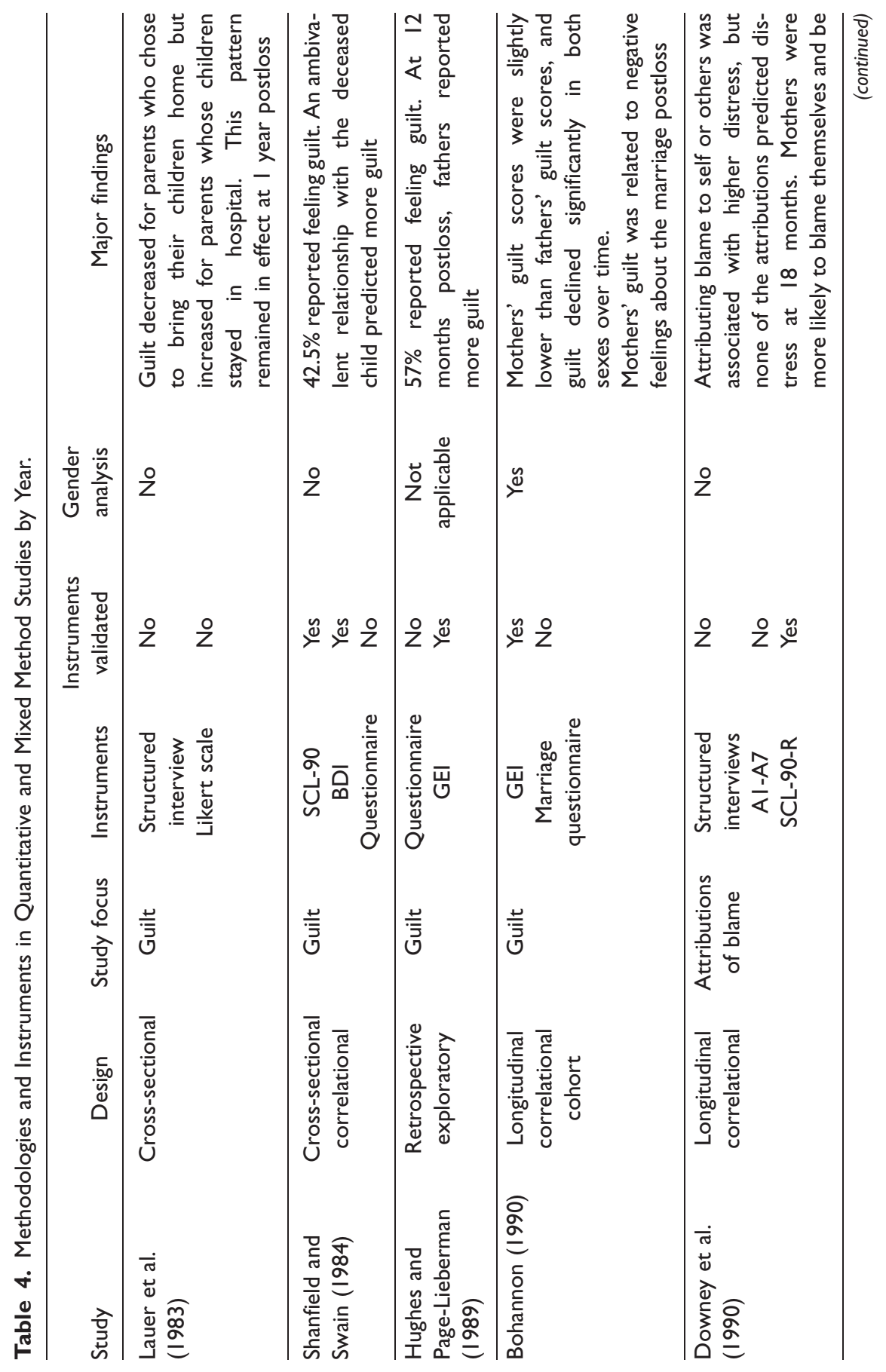




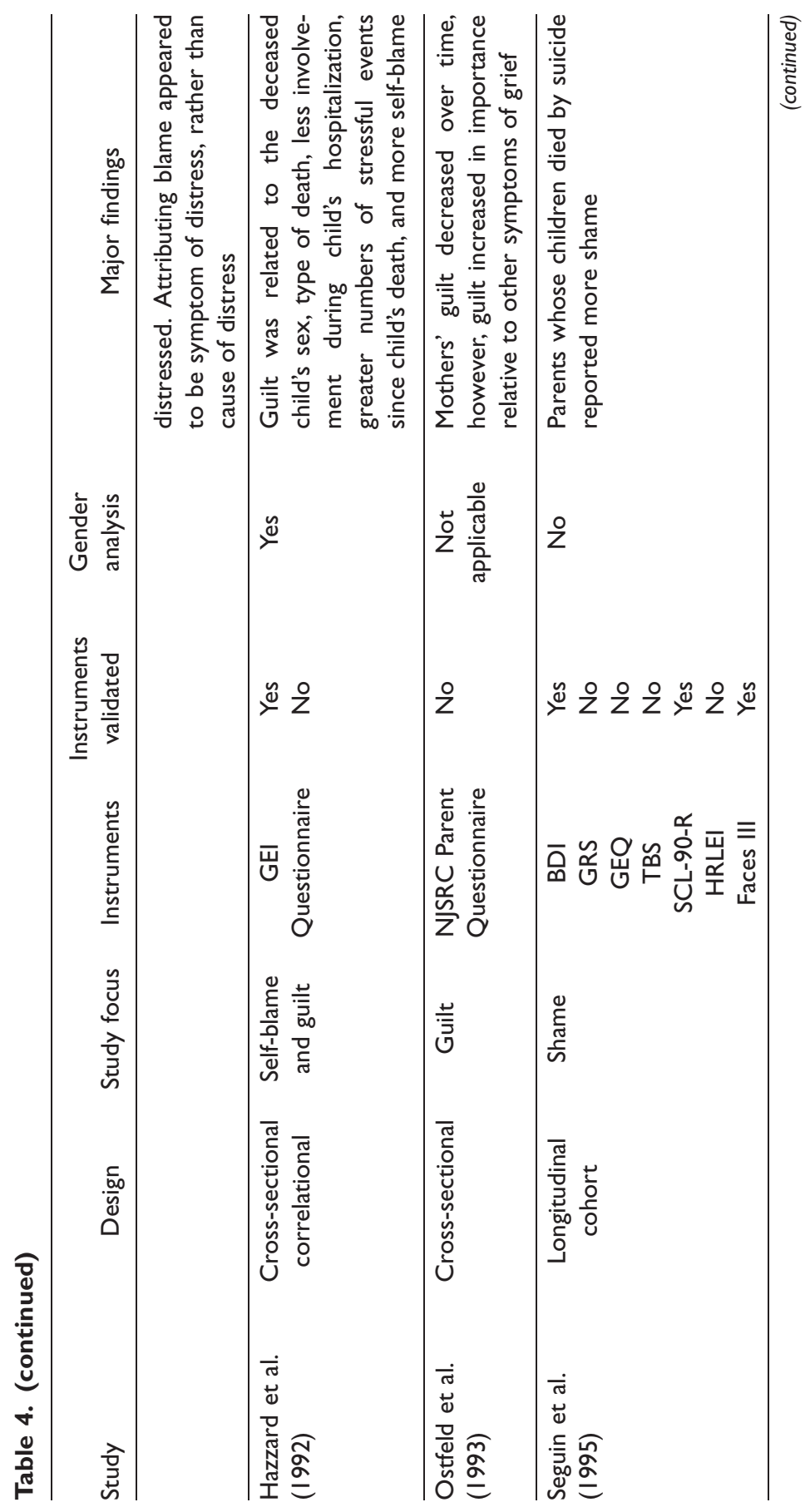




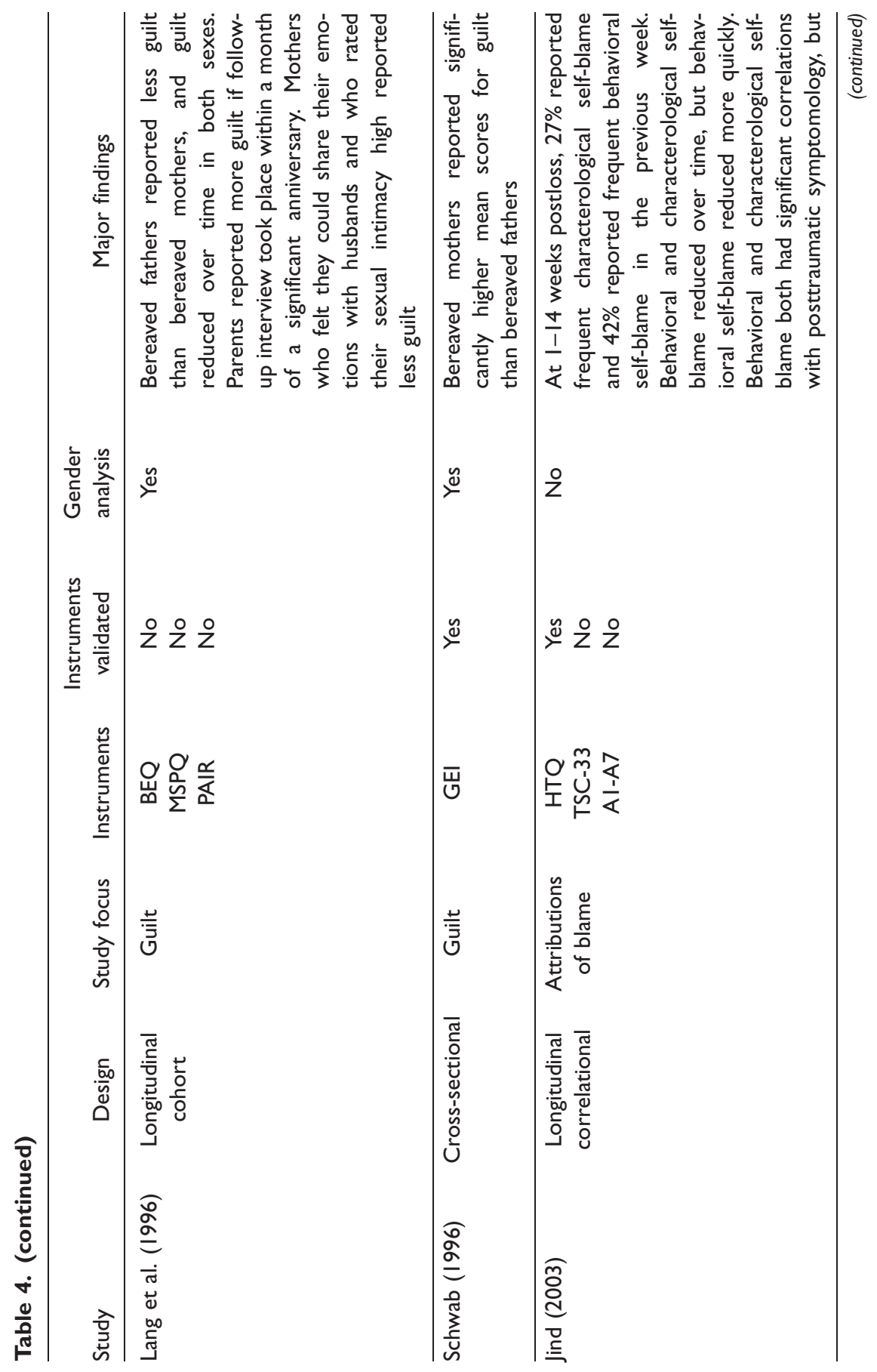




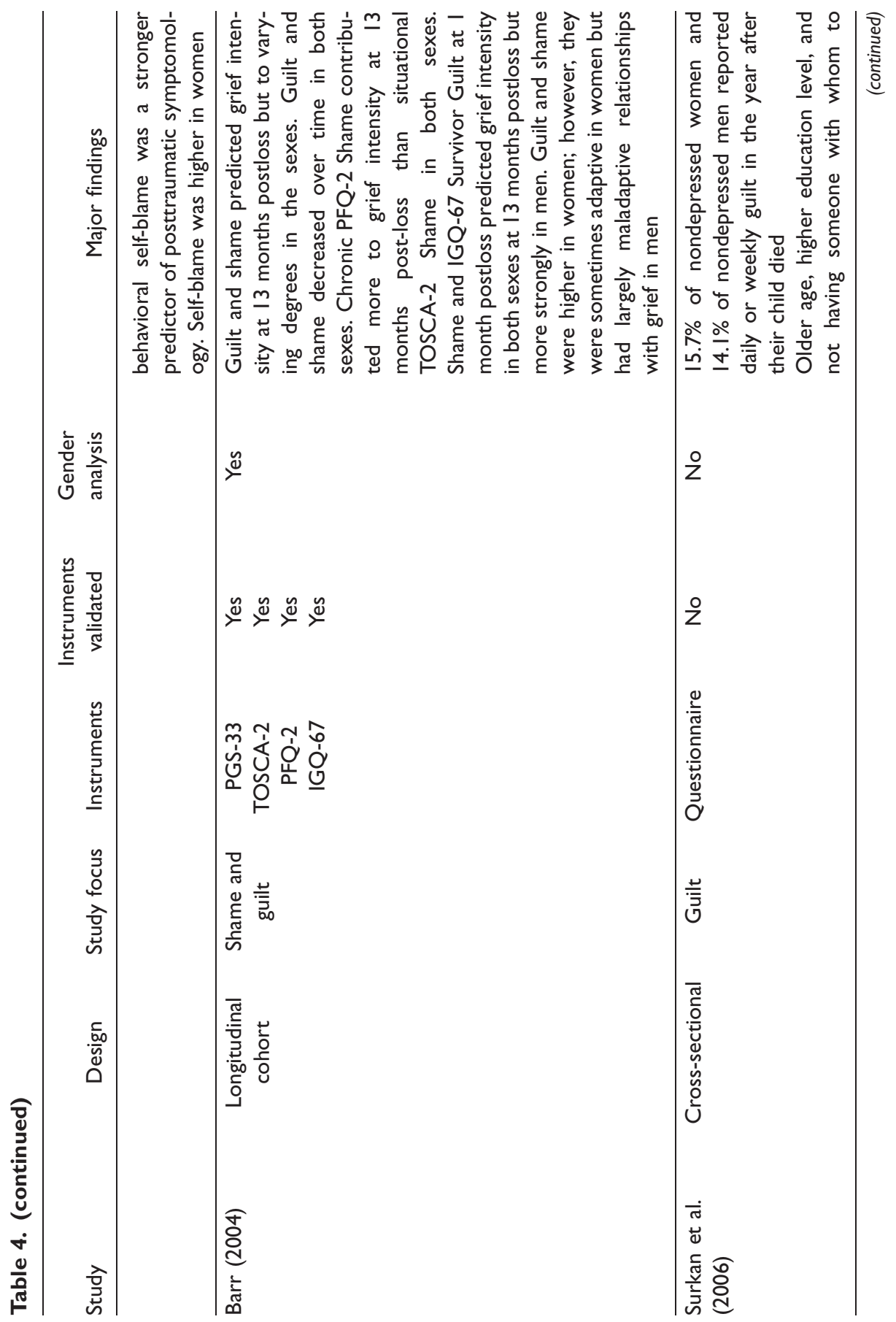




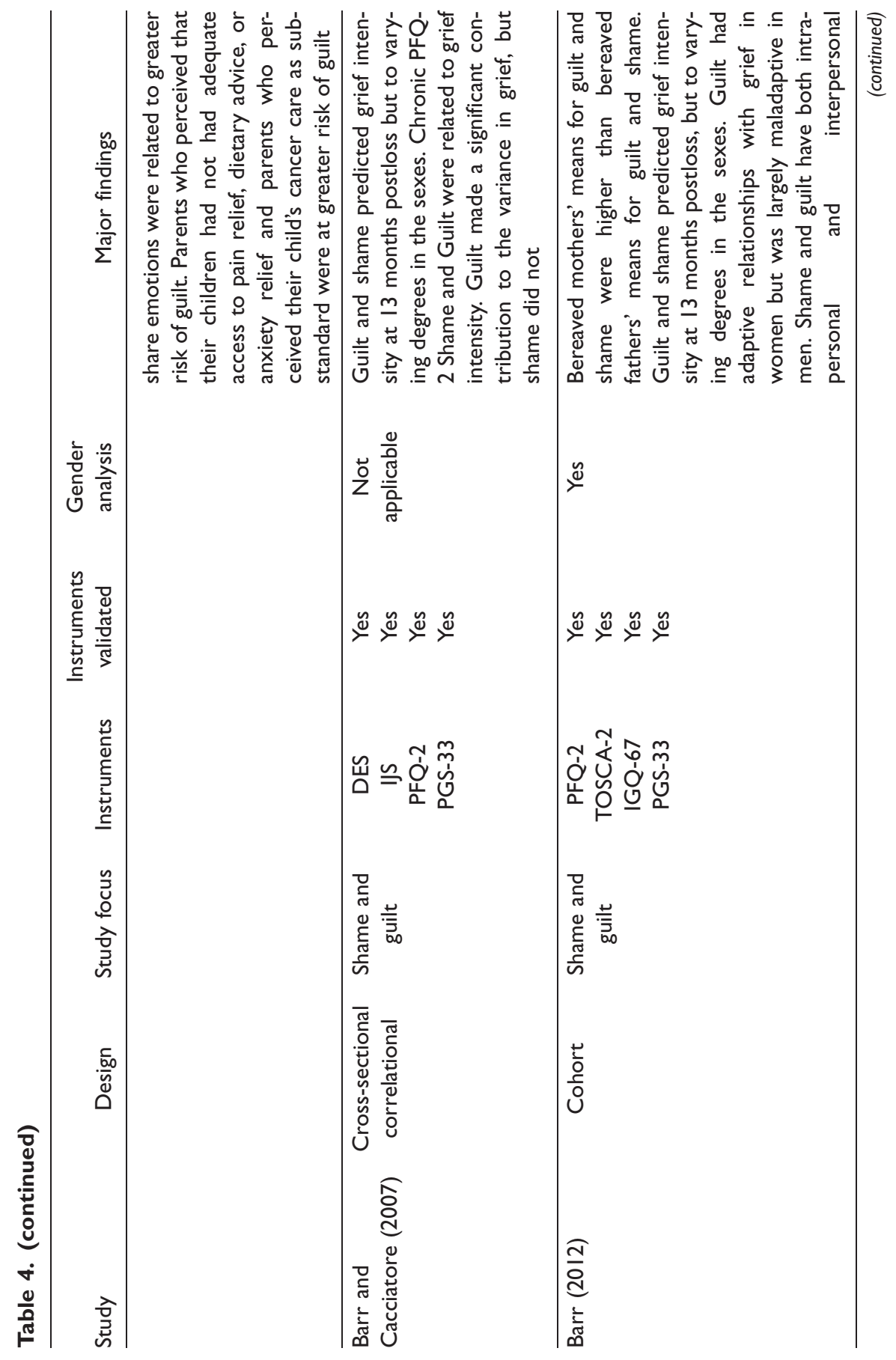




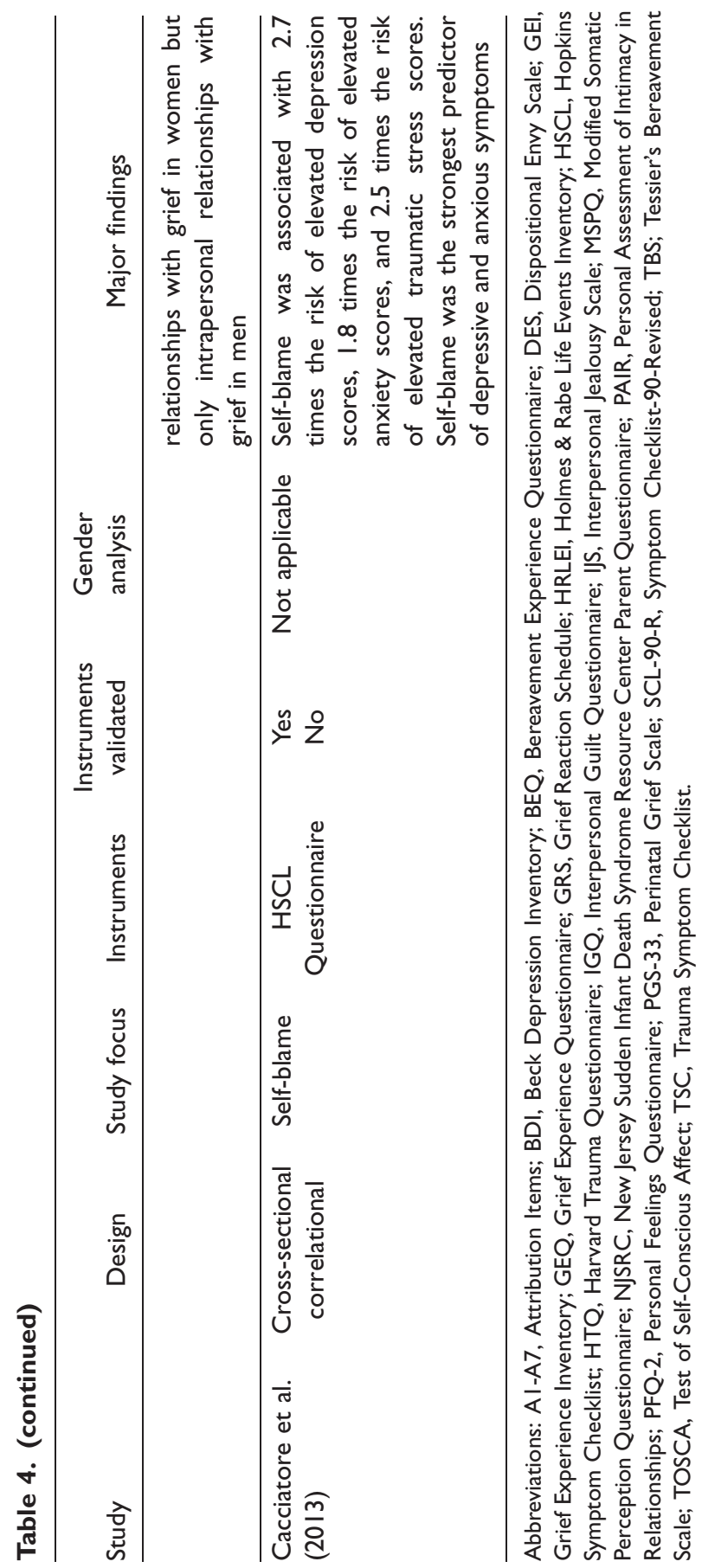




\section{Study Findings}

Prevalence of self-blame, guilt, and shame in bereaved parents. Percentages of bereaved parents reporting behavioral self-blame ranged from 51\% (Downey et al., 1990) to $42.4 \%$ (Jind, 2003) in acute loss and reduced to 26\% (Downey et al., 1990) and $23.1 \%$ (Jind, 2003), respectively, over time. Percentages of bereaved parents reporting characterological self-blame ranged from 45\% (Downey et al., 1990) to $27.2 \%$ (Jind, 2003) in early loss and declined to 20\% (Downey et al., 1990) and $15.4 \%$ (Jind, 2003), respectively, over time. Cacciatore, Froen, and Killian (2013) reported that $24.6 \%$ of the bereaved mothers in their study blamed themselves for their baby's death; however, the study did not distinguish between characterological and behavioral self-blame.

Percentages of bereaved parents who reported guilt were 14.1\% (bereaved fathers; Surkan et al., 2006), 15.7\% (bereaved mothers; Surkan et al., 2006), 42.5\% (bereaved parents; Shanfield \& Swain, 1984), 57\% (bereaved parents; Miles \& Demi, 1983), and 57\% (bereaved fathers; Hughes \& Page-Lieberman, 1989). Owing to differences in the operationalization of self-blame, guilt, and shame, these figures cannot be synthesized into a single estimate of prevalence. Other studies reported on the means for guilt and shame instead, but most of the studies did not utilize control groups of nonbereaved or people experiencing other types of loss. In the three studies that did make comparisons with control groups or normed groups, findings varied (Hazzard et al., 1992; Hughes \& PageLieberman, 1989; Lang et al., 1996).

Differences in self-blame, guilt, and shame in the sexes. All six studies that compared the sexes reported higher self-blame, guilt, and shame in bereaved mothers. Interestingly, Barr $(2004,2012)$ reported that guilt was largely adaptive in women and maladaptive in men. So, while mothers may experience more guilt than fathers, guilt may be more problematic for fathers than mothers. Bereaved mothers' guilt was associated with negative feelings about their marriage (Bohannon, 1990) and reduced sexual intimacy (Lang et al., 1996), but no significant relationships were found between fathers' guilt and the marital relationship. Barr (2012) reported that bereaved mothers' grief was affected by their partner's shame and guilt but bereaved fathers' grief was not.

Self-blame, guilt, and shame, and their relationships with situational or demographic variables. Three studies found relationships between guilt and the care provided to sick children before their death. Guilt decreased significantly for parents who chose to bring their children home for palliative care, while guilt increased significantly for parents whose children remained hospitalized. One year after the child's death, guilt remained low in parents who had provided home care and high for parents whose children had been hospitalized (Lauer et al., 1983). Guilt was associated with less involvement in the child's caregiving at the end of life 
(Hazzard et al., 1992), and parents who perceived that their children were without adequate pain and anxiety relief and competent medical care were at greater risk of experiencing guilt (Surkan et al., 2006). Sudden child death was related to increased guilt (Hazzard et al., 1992), while parents whose children died by suicide reported more shame than parents whose children died accidentally (Seguin et al., 1995). Mothers and fathers both reported more guilt when the follow-up interview took place within a month of a significant anniversary (Lang et al., 1996). Finally, increased guilt was also associated with a greater number of stressful events since the child's death, more self-blame (Hazzard et al., 1992), older age, higher education level, and the absence of someone safe with whom to share emotions (Surkan et al., 2006).

Self-blame, guilt, and shame, and their relationships with measures of psychological adaptation after loss. Seven studies analyzed the relationships between self-blame, guilt, and shame and psychological adaptation after loss (Barr, 2004, 2012; Barr \& Cacciatore, 2007; Cacciatore et al., 2013; Downey et al., 1990; Hazzard et al., 1992; Jind, 2003). Attributing blame to self or others was associated with higher distress, but by 18 months postloss, none of the attributions predicted distress (Downey et al., 1990). Both behavioral and characterological self-blame had significant positive correlations with posttraumatic symptoms, but behavioral self-blame was a stronger predictor (Jind, 2003). Self-blame was associated with a 2.7 times higher risk of depressive scores and 1.8 times higher risk of anxious symptoms (Cacciatore et al., 2013). Self-blame was also related to somatization, and significant positive correlations were reported between guilt and despair, anger-hostility, and depersonalization (Hazzard et al., 1992).

Guilt and shame predicted grief intensity at 13 months postloss, albeit to varying degrees in each of the sexes (Barr, 2004, 2012; Barr \& Cacciatore, 2007). All types of shame and guilt together explained $45 \%$ of the variance in women's grief intensity and $63 \%$ of the variance in men's grief intensity at 13 months postloss (Barr, 2004). Survivor guilt predicted grief intensity in both sexes at 13 months postloss but more strongly in men (Barr, 2004, 2012).

Strategies for managing self-blame, guilt, and shame. Only one study explored strategies for managing self-blame, guilt, or shame. Miles and Demi (1983) reported that bereaved parents used rationalizing, sharing, religion, keeping busy, reading/writing, biding time, avoiding, and forgiving self to mitigate their guilt.

\section{Discussion}

There is sufficient evidence that self-blame, guilt, and shame are commonplace in the experience of bereaved parents; however, is also evidence that many bereaved parents do not report self-blame, guilt, or shame. Studies that used validated scenario-based instruments or adjective lists and that did not constrain 
the participants to report on a very limited time period may be more sensitive measures of the prevalence of guilt and shame (Barr, 2004, 2012; Barr \& Cacciatore, 2007). The fact that many studies did not discuss the effects of time since loss may also explain the range of prevalence since these affective states tend to diminish over time in both sexes. Guilt was higher in those diagnosed with MDD, which is not surprising considering that guilt is listed in the criteria for the diagnosis of MDD.

At first glance, there appears to be strong evidence that women experience more self-blame, guilt, and shame than men. However, grief scales such as those used to assess guilt and shame in many of these studies may be biased toward identifying feminine forms of grief expression and underidentifying grief symptoms in fathers (Cook, 1988). There is evidence that women's grief is affected by their partner's shame and guilt and the quality of the marital relationship, while this is not the case for men. A possible theoretical explanation for this is that shame and guilt function to preserve interpersonal relationships (Baumeister et al., 1994; Behrendt \& Ben-Ari, 2012), something about which women tend to be highly concerned. While bereaved mothers report more guilt and shame than bereaved fathers, guilt and shame appear more problematic for men. Perhaps women are more likely to employ strategies that help ease guilt and shame, such as making amends, sharing their experiences with others, or accessing counseling support (Brown, 2006; Baumeister et al., 1994; Kubany \& Watson, 2003). There is strong evidence that guilt and shame predict grief intensity (Barr, 2004, 2012; Barr \& Cacciatore, 2007), while self-blame may be related to anxious, depressive, and posttraumatic symptomology (Cacciatore et al., 2013; Jind, 2003).

None of the studies in this review sought to understand why self-blame, guilt, and shame occur in bereavement. Kauffman (1996) argues that shame stems from powerlessness, and death is the ultimate reminder of the limits of human power:

How any particular individual characteristically responds to powerlessness is a function of prior affect socialization, the relative dominance of one or more affects with the personality, the prevalence of shame itself, and the emergent strategies of avoidance and escape from shame. (Kauffman, 1996, pp. 53-54)

Kauffman (1996) also theorizes that shame results from disruptions in relationships and failure to meet one's own expectations. According to Schermer (2010), "Shame becomes related to mourning insofar as death and dying are perceived as isolation from human interaction and an exile from human contact" (p. 41). Shame can be problematic in grief, playing "a significant, though not exclusive, role in the damage to an individual's sense of self and the denial of loss that complicates and pathologizes the mourning process" (Schermer, 2010, p. 52). 
Kubany and Watson (2003) propose a multidimensional model of traumarelated guilt wherein the magnitude of a person's guilt is a combined function of emotional distress and four cognitive beliefs: (a) personal responsibility in causing the negative outcome, (b) insufficient justification for one's actions, (c) a violation of one's own values or morals, and (d) a belief that a reasonable person should have foreseen and thus prevented the events that led to the negative outcome. Guilt and shame are intimately related in that, "When survivors implicate themselves as playing a significant role in tragic, irreparable outcomes, they are also prone to conclude that the outcomes reflect on their entire selves, personality or character..." (Kubany \& Watson, 2003, p. 72). This model may help explain why so many bereaved parents report guilt and shame after a child's death, particularly in the case of suicide and unanticipated death (Hazzard et al., 1992; Seguin et al., 1995; Shanfield \& Swain, 1984). Perhaps being involved and satisfied with the care provided to a terminally ill child helps to alleviate guilt by mitigating these four cognitive beliefs (Hazzard et al., 1992; Lauer et al., 1983; Surkan et al., 2006).

Socially constructed judgments about what constitutes normative grieving may incite shame and guilt for a grieving parent. Klass and Chow (2011, p. 341) note that "culture polices grief" by proscribing which meanings and practices are considered to be unacceptable, abnormal, or pathological. Harris (2009) agrees that bereaved people are often oppressed by grief standards informed by modern Western values of productivity, competition, and consumerism. Shame may be one of the important differences between bereaved people who require counseling support and those who do not (Harris, 2009). Klass and Chow assert that the problem lies, not with the bereaved, but rather, "how others judge how they are doing" (p. 350).

Overall, there is evidence that self-blame, guilt, and shame are commonplace and related to anxious, depressive, and posttraumatic symptomology in bereaved parents. However, there are a great many unanswered questions. The evidence is limited by heterogenous definitions, and many of the instruments used may not be valid for measuring self-blame, guilt, and shame in parental bereavement. A few of the recent studies are notable exceptions offering stronger evidence because they have used more robust study designs and instruments specifically developed for measuring guilt and shame (Barr, 2004, 2012; Barr $\&$ Cacciatore, 2007).

\section{Review Limitations}

This systematic review is subject to publication bias because papers with statistically significant findings are more likely to be published, and we only included peer-reviewed and published studies. The decision to exclude exploratory qualitative studies means that this review has not captured some of the rich qualitative knowledge available in respect of self-blame, guilt, and shame. We also excluded papers that were not published in English, which limits cultural 
perspectives. Finally, the heterogenous nature of the designs and instruments used in the selected studies, together with the low number of relevant studies, precluded us from doing a meta-analysis of the study findings.

\section{Authors' Conclusions}

\section{Implications for Practice}

Practitioners supporting bereaved parents need to be aware that self-blame, guilt, and shame are common in parental bereavement and may be especially relevant in treatment of bereaved parents who are seeking counseling support for anxious, depressive, or posttraumatic symptomology. While none of the studies addressed questions related to interventions, other authors have offered helpful guidance. Tangney and Salovey (1999) argue that the duration and pervasiveness of guilt and shame, the appropriateness of these emotions to their situational triggers, and the individual's competence in managing guilt and shame are useful dimensions for understanding support needs.

Exploring, acknowledging, and deconstructing guilt- and shame-inducing socially constructed assumptions in the aftermath of loss should be an important focus of bereavement support interventions (Brown, 2006; Harris, 2009; Humphrey, 2009). Couple-focused therapy and group interventions may be particularly effective for helping bereaved parents to develop shame resilience (Brown, 2006).

Guilt may be alleviated by apologizing, making amends, forgiving oneself or being forgiven, and contemplating thinking patterns that contribute to guilt (Kubany \& Watson, 2003; Weinberg, 1995). Parental involvement in end-of-life caregiving, when possible, should be encouraged. Martin and Doka (2011) suggest that people with an instrumental grieving style may find therapeutic reconciliation rituals and active ways of making amends particularly helpful in alleviating guilt. Guilt and shame in bereavement are often a result of an overestimation of one's ability to exercise mastery and control in the loss event, and therefore, assistance with a more accurate appraisal of responsibility can help to alleviate guilt and shame (Humphrey, 2009; Martin \& Doka, 2011). However, some parents do, indeed, contribute to their children's death, even if inadvertently. For these parents, Cacciatore and Flint (2012) suggest clinical interventions using a mindfulness-based approach that focuses on bearing witness to the tragic events leading to the child's death, acknowledging one's responsibility in a safe milieu, building affect and memory tolerance, and turning attention toward redemptive acts.

\section{Implications for Research}

Studies in this review have approached grief and self-blame, guilt, and shame as individual intrapersonal phenomena. As gender and culture seem to affect 
self-blame, guilt, and shame (Else-Quest, Higgins, Allison, \& Mortion, 2012; Oltjenbruns, 2010), further gender, regional, and cultural analyses would be advised. In addition, time since loss, circumstances of loss, and the child's age should be more closely analyzed.

The relationship between Janoff-Bulman's (1979) constructs of behavioral and characterological self-blame attributions and Tangney et al.'s (1996) constructs of guilt and shame require further research, as the findings in that regard have been inconsistent (Jind, 2003; Tilghman-Osborne et al., 2008). None of the research designs included measures of positive adaptation, so it is possible that adaptive functions of self-blame, guilt, and shame in bereavement have not been captured (Baumeister et al., 1994; Tangney \& Salovey, 1999). Studies of self-blame, guilt, and shame and posttraumatic growth in parents with babies in neonatal intensive care unit have reported that optimum levels of shame were associated with posttraumatic growth while lower or higher levels were not (Barr, 2011; Tennen, Affleck, \& Gershman, 1986). Further exploration of the adaptive nature of selfblame, guilt, and shame and strategies for managing them could inform strengthbased psychoeducational programs to support bereaved parents.

Finally, while the quantitative approach used in most of these studies provides information about trends and commonalities, it has a tendency to silence the heterogeneities. Qualitative approaches may be better suited to learning about the unique, subjective, and diverse experiences of bereaved parents and for explaining the intrapersonal, interpersonal, and cultural processes through which self-blame, guilt, and shame are related to various outcomes. Stroebe, Stroebe, and Schut (2003) advocate for the value of mixed method approaches wherein in-depth qualitative exploration is followed by quantitative evaluation and validation. Prospective, in-depth, longitudinal designs that include matched nonbereaved control groups may be one of the more suitable and rigorous research designs for pursuing quantitative questions.

\section{Conclusion}

This review found sufficient evidence that self-blame, guilt, and shame are commonplace and related to more intense and enduring parental grief. However, there is insufficient data to determine why this is the case or how self-blame, guilt, and shame in bereaved parents differ from other populations. In general, studies in this area can improve their methodology, bringing strength and generalizability to their findings. A number of recommendations have been made for improvements to study methodologies and directions for future research in this important arena of bereavement.

\section{Declaration of Conflicting Interests}

The author(s) declared no potential conflicts of interest with respect to the research, authorship, and/or publication of this article. 


\section{Funding}

The author(s) received no financial support for the research, authorship, and/or publication of this article.

\section{References}

References marked with an asterisk indicate studies included in the meta-analysis.

Adolfsson, A., Larsson, P. G., Wijma, B., \& Bertero, C. (2004). Guilt and emptiness: Women's experiences of miscarriage. Health Care for Women International, 25, 543-560.

Alexander, B., Brewin, C. R., Vearnals, S., Wolff, G., \& Leff, J. (1999). An investigation of shame and guilt in a depressed sample. British Journal of Medical Psychology, 72, 323-338.

American Psychiatric Association. (2000). Diagnostic and statistical manual of mental disorders (4th ed., text rev.). Washington, DC: Author.

Andrews, B. (1998). Methodological and definitional issues in shame research. In P. Gilbert \& B. Andres (Eds), Shame: Interpersonal behavior, psychopathology and culture (pp. 39-54). New York, NY: Oxford University Press.

*Barr, P. (2004). Guilt- and shame-proneness and the grief of perinatal bereavement. Psychology and Psychotherapy: Theory, Research and Practice, 77, 493-510.

Barr, P. (2011). Posttraumatic growth in parents of infants hospitalized in a neonatal intensive care unit. Journal of Loss and Trauma, 16, 117-134.

*Barr, P. (2012). Negative self-conscious emotion and grief: An actor-partner analysis in couples bereaved by stillbirth or neonatal death. Psychology and Psychotherapy: Theory, Research and Practice, 85, 310-326.

*Barr, P., \& Cacciatore, J. (2007). Problematic emotions and maternal grief. Omega, 56, 331-348.

Barrett, T. W., \& Scott, T. B. (1990). Suicide bereavement and recovery patterns compared with non-suicide bereavement patterns. Suicide and Life-Threatening Behavior, 20, $1-15$.

Baumeister, R. F., Stillwell, A. M., \& Heatherton, T. F. (1994). Guilt: An interpersonal approach. Psychological Bulletin, 115, 243-267.

Behrendt, H., \& Ben-Ari, R. (2012). The positive side of negative emotion: The role of guilt and shame in coping with interpersonal conflict. Journal of Conflict Resolution, $56,1116-1138$.

Blum, A. (2008). Shame and guilt, misconceptions and controversies: A critical review of the literature. Traumatology, 14, 91-102.

*Bohannon, J. R. (1990). Grief responses of spouses following the death of a child: A longitudinal study. Omega, 22, 109-121.

Broen, A. N., Moum, T., Bodtker, A. S., \& Ekeberg, O. (2004). Psychological impact on women of miscarriage versus induced abortion: A 2-year follow-up study. Psychosomatic Medicine, 66, 265-271.

Broucek, F. J. (1991). Shame and the self. New York, NY: Guildford Press.

Brown, B. (2006). Shame resilience theory: A grounded theory study on women and shame. Families in Society, 87, 43-52. 
Bryan, C. J., Ray-Sannerud, B., Morrow, C. E., \& Etienne, N. (2013). Guilt is more strongly associated with suicidal ideation among military personnel with direct combat exposure. Journal of Affective Disorders, 148, 37-41.

Buckle, J. L., \& Fleming, S. J. (2011). Parenting challenges after the death of a child. In R. A. Neimeyer, D. L. Harris, H. R. Winokuer \& G. F. Thornton (Eds), Grief and bereavement in contemporary society. Bridging research and practice (pp. 93-105, chap. 9). New York, NY: Routledge.

Cacciatore, J., \& Flint, M. (2012). ATTEND: Toward a mindfulness-based bereavement care model. Death Studies, 36, 61-82.

*Cacciatore, J., Froen, F., \& Killian, M. (2013). The effects of self-blame on anxiety and depression among women who have experienced stillbirth. Journal of Mental Health Counseling, 35(4), 342-359.

Clyman, R. I., Green, C., Rowe, J., Mikkelsen, C., \& Ataide, L. (1980). Issues concerning parents after the death of their newborn. Critical Care Medicine, 8, 215-218.

Cook, J. A. (1988). Dad's double binds: Rethinking fathers' bereavement from a men's studies perspective. Journal of Contemporary Ethnography, 17, 285-308.

DeFrain, J., Martens, L., Stork, J., \& Stork, W. (1990). The psychological effects of a stillbirth on surviving family members. Omega, 22, 81-108.

DeFrain, J., Millspaugh, E., \& Xie, X. (1996). The psychological effects of miscarriage: Implications for health professionals. Families, Systems and Health, 14, 331-347.

Demi, A. S., \& Schroeder, M. A. (1987). Bereavement experience questionnaire. Unpublished manuscript. Georgia State University, Atlanta.

*De Tychey, C., \& Dollander, M. A. (2007). Maternal resilience and chronic depression in mourning for a child: A preliminary case-based analysis. Rorschachiana, 28, 16-35.

Dickerson, S. S., Gruenewal, T. L., \& Kemeny, M. E. (2004). When the social self is threatened: Shame, physiology, and health. Journal of Personality, 72, 1191-1216.

*Downey, G., Silver, R. C., \& Wortman, C. B. (1990). Reconsidering the attributionadjustment relation following a major negative event: Coping with the loss of a child. Journal of Personality and Social Psychology, 59, 925-940.

Else-Quest, N. M., Higgins, A., Allison, C., \& Mortion, L. C. (2012). Gender differences in self-conscious emotional experience: A meta-analysis. Psychological Bulletin, 138, 947-981.

Fergus, T. A., Valentiner, D. P., McGrath, P. B., \& Jencius, S. (2010). Shame- and guiltproneness: Relationships with anxiety disorder symptoms in a clinical sample. Journal of Anxiety Disorders, 24, 811-815.

Frost, M., \& Condon, J. T. (1996). The psychological sequelae of miscarriage: A critical review of the literature. Australian and New Zealand Journal of Psychiatry, 30, 54-62.

Garb, H. N., Wood, J. M., Lilienfeld, S. O., \& Nezworski, M. T. (2005). Roots of the Rorschach controversy. Clinical Psychology Review, 25, 97-118.

Garb, H. N., Wood, J. M., Nezworski, M. T., Grove, W. M., \& Stejskal, W. J. (2001). Toward a resolution of the Rorschach controversy. Psychological Assessment, 13, 433-448.

Ghatavi, K., Nicolson, R., MacDonald, C., Osher, S., \& Levitt, A. (2002). Defining guilt in depression: A comparison of subjects with major depression, chronic medical illness and health controls. Journal of Affective Disorders, 68, 307-315. 
Goss, K., \& Allan, S. (2009). Shame, pride and eating disorders. Clinical Psychology and Psychotherapy, 16, 303-316.

Grabe, S., Hyde, J. S., \& Lindberg, S. M. (2007). Body objectification and depression in adolescents: The role of gender, shame and rumination. Psychology of Women Quarterly, 31, 164-175.

Harder, D. W., Cutler, L., \& Rockart, L. (1992). Assessment of shame and guilt and their relationships to psychopathology. Journal of Personality Assessment, 59, 584-604.

Harder, D. W., \& Lewis, S. J. (1987). The assessment of shame and guilt. In J. N. Butcher \& C. D. Spielberger (Eds), Advances in personality assessment (Vol. 6, pp. 89-114). Hillsdale, NJ: Lawrence Erlbaum.

Harris, D. (2009). Oppression of the bereaved: A critical analysis of grief in Western society. Omega, 60, 241-253.

Hasui, C., \& Kitamaru, T. (2004). Aggression and guilt during mourning by parents who lost an infant. Bulletin of the Menninger Clinic, 68, 245-259.

*Hazzard, A., Weston, J., \& Gutterres, C. (1992). After a child's death: Factors related to parental bereavement. Developmental and Behavioral Pediatrics, 13, 24-30.

Hiller, J. B., Rosenthal, R., Bornstein, R. F., Berry, D. T. R., \& Brunell-Neuleib, S. (1999). A comparative meta-analysis of Rorschach and MMPI validity. Psychological Assessment, 11, 278-296.

Hoglund, C. L., \& Nicholas, K. B. (1995). Shame, guilt, and anger in college students exposed to abusive family environments. Journal of Family Violence, 10, 141-157.

Hsu, M., Tseng, Y., Banks, J. M., \& Kuo, L. (2004). Interpretations of stillbirth. Journal of Advanced Nursing, 47, 408-416.

*Hughes, C. B., \& Page-Lieberman, J. (1989). Fathers experiencing a perinatal loss. Death Studies, 13, 537-556.

Humphrey, K. M. (2009). Counseling strategies for loss and grief. Alexandria, VA: American Counseling Association.

Janoff-Bulman, R. (1979). Characterological versus behavioral self-blame. Inquiries into depression and rape. Journal of Personality and Social Psychology, 37, 1798-1809.

*Jind, L. (2003). Parents' adjustment to late abortion, stillbirth and infant death. The role of causal attributions. Scandinavian Journal of Psychology, 44, 383-394.

Jind, L., Elklit, A., \& Christiansen, D. (2010). Cognitive schemata and processing among parents bereaved by infant death. Journal of Clinical Psychology in Medical Settings, 17, 366-377.

Jordan, J. R., Baker, J., Matteis, M., Rosenthal, S., \& Ware, E. S. (2005). The Grief Evaluation Measure (GEM): An initial validation study. Death Studies, 29, 301-332.

Kauffman, G. (1996). The psychology of shame. Theory and treatment of shame-based syndromes (2nd ed.). New York, NY: Springer.

Kim, S., Thibodeau, R., \& Jorgensen, R. S. (2011). Shame, guilt, and depressive symptoms: A meta-analytic review. Psychological Bulletin, 137, 68-96.

Klass, D., \& Chow, A. Y. M. (2011). Culture and ethnicity in experiencing, policing, and handling grief. In R. A. Neimeyer, D. L. Harris, H. R. Winokuer \& G. F. Thornton (Eds), Grief and bereavement in contemporary society. Bridging research and practice (pp. 341-353, chap. 26). New York, NY: Routledge.

Kubany, E. S., \& Watson, S. B. (2003). Guilt: Elaboration of a multidimensional model. The Psychological Record, 53, 51-90. 
*Lang, A., Gottlieb, L. N., \& Amsel, R. (1996). Predictors of husband' and wives' grief reactions following infant death: The role of marital intimacy. Death Studies, 20, $33-57$.

*Lauer, M. E., Mulhern, R. K., Wallskog, J. M., \& Camitta, B. M. (1983). A comparison study of parental adaptation following a child's death at home or in the hospital. Pediatrics, 71, 107-112.

Leskela, J., Dieperink, M., \& Thuras, P. (2002). Shame and posttraumatic stress disorder. Journal of Traumatic Stress, 15, 223-226.

Lester, D. (1998). The association of shame and guilt with suicidality. The Journal of Social Psychology, 134, 535-536.

Lewis, H. B. (1971). Shame and guilt in neurosis. New York, NY: International Universities Press.

Lutwak, N., Panish, J., \& Ferrari, J. (2003). Shame and guilt: Characterological vs. behavioral self-blame and their relationship to fear of intimacy. Personality and Individual Differences, 35, 909-916.

Luyten, P., Fontaine, J. R. J., \& Corveleyn, J. (2002). Does the Test of SelfConscious Affect (TOSCA) measure maladaptive aspects of guilt and adaptive aspects of shame? An empirical investigation. Personality and Individual Differences, 33, $1373-1387$.

Mandell, F., McAnulty, E., \& Reece, R. M. (1980). Observations of paternal response to sudden unanticipated infant death. Pediatrics, 65, 221-226.

Martin, T. L., \& Doka, K. J. (2011). The influence of gender and socialization on grieving styles. In R. A. Neimeyer, D. L. Harris, H. R. Winokuer \& G. F. Thornton (Eds), Grief and bereavement in contemporary society. Bridging research and practice (pp. 69-77, chap. 7). New York, NY: Routledge.

* Miles, M. S., \& Demi, A. S. (1983). Toward the development of a theory of bereavement guilt: Sources of guilt in bereaved parents. Omega, 14, 299-314.

Miles, M. S., \& Demi, A. S. (1986). Guilt in bereaved parents. In T. A. Rando (Ed.), Parental loss of a child (pp. 97-118). Champaign, IL: Research Press Company.

Mulrow, C. D. (1994). Rationale for systematic reviews. British Medical Journal, 309, 597-599.

O’Connor, L. E., Berry, J. W., Weiss, J., Bush, M., \& Sampson, H. (1997). Interpersonal guilt: The development of a new measure. Journal of Clinical Psychology, 53, 73-89.

Oltjenbruns, K. A. (2010). Ethnicity and the grief response: Mexican American versus Anglo American college students. Death Studies, 22, 141-155.

*Ostfeld, B. M., Ryan, T., Hiatt, M., \& Heygi, T. (1993). Maternal grief after sudden infant death syndrome. Developmental and Behavioral Pediatrics, 14, $156-162$.

Pai, M., McCulloch, M., Gorman, J. D., Pai, N., Enanoria, W., Kennedy, G., ... Colford, J. M. (2004). Systematic reviews and meta-analyses: An illustrated, step-by-step guide. The National Medical Journal of India, 17, 86-95.

Parker, K. C. H., Hanson, R. K., \& Hunsley, J. (1988). MMPI, Rorschach, and WAIS: A meta-analytic comparison of reliability, stability, and validity. Psychological Bulletin, 103, 367-373.

Peterson, C., Schwartz, S. M., \& Seligman, M. E. P. (1981). Self-blame and depressive symptoms. Journal of Personality and Social Psychology, 41, 253-259. 
Popay, J., Rogers, A., \& Williams, G. (1998). Rationale and standards for the systematic review of qualitative literature in health services research. Qualitative Health Research, 8, 341-351.

Potvin, L., Lasker, J., \& Toedter, L. (1989). Measuring grief: A short version of the Perinatal Grief Scale. Journal of Psychopathology and Behavioral Assessment, 11, 29-45.

Prigerson, H. G., Maciejewski, P. K., Reynolds, C. F., Bierhals, A. J., Newsom, J. T., Fasiczka, A., ... Miller, M. (1995). Inventory of complicated grief: A scale to measure maladaptive symptoms of loss. Psychiatry Research, 59, 65-79.

Rando, T. A. (1986). Parental loss of a child. Champaign, IL: Research Press Company.

Reagan, L. J. (2003). From hazard to blessing to tragedy: Representations of miscarriage in twentieth-century America. Feminist Studies, 29, 357-378.

Rizvi, S. L. (2010). Development and preliminary validation of a new measure to assess shame: The shame inventory. Journal of Psychopathology and Behavioral Assessment, 32, 438-447.

Robinson, G. E. (2011). Dilemmas related to pregnancy loss. The Journal of Nervous and Mental Disease, 199, 571-574.

Rortveit, K., Astrom, S., \& Severinsson, E. (2010). The meaning of guilt and shame: A qualitative study of mothers who suffer from eating difficulties. International Journal of Mental Health Nursing, 19, 231-239.

Samuelsson, M., Radestad, I., \& Segesten, K. (2001). A waste of life: Fathers' experience of losing a child before birth. Birth, 28, 124-130.

Sanders, C., Mauger, P., \& Strong, P. (1985). A manual for the grief experience inventory. Palo Alto, CA: Consulting Psychologists Press.

Scheff, T. (2012). A social/emotional theory of 'mental illness'. International Journal of Social Psychiatry, 59, 87-92.

Scheff, T. J. (2000). Shame and the social bond: A sociological theory. Sociological Theory, 18, 84-99.

*Schwab, R. (1996). Gender differences in parental grief. Death Studies, 20, 102-113.

*Seguin, M., Lesage, A., \& Kiely, M. C. (1995). Parental bereavement after suicide and accident: A comparative study. Suicide and Life-Threatening Behavior, 25, 489-498.

*Shanfield, S. B., \& Swain, B. J. (1984). Death of adult children in traffic accidents. The Journal of Nervous and Mental Disease, 172, 533-538.

Silfver, M. (2007). Coping with guilt and shame: A narrative approach. Journal of Moral Education, 36, 169-183.

Smialek, Z. (1978). Observations on immediate reactions of families to sudden infant death. Pediatrics, 62, 160-165.

Street, A. E., \& Arias, I. (2001). Psychological abuse and posttraumatic stress disorder in battered women: Examining the roles of shame and guilt. Violence and Victims, 16, 65-78.

Stroebe, M., Stroebe, W., \& Schut, H. (2003). Bereavement research: Methodological issues and ethical concerns. Palliative Medicine, 17, 235-240.

*Surkan, P. J., Kreicbergs, U., Valdimarsdottir, U., Nyberg, U., Onelove, E., Dickman, P. W., ... Steineck, G. (2006). Perceptions of inadequate health care and feelings of guilt in parents after the death of a child to a malignancy: A population-based longterm follow-up. Journal of Palliative Medicine, 9, 317-331. 
Tangney, J. P., \& Dearing, R. (2002). Shame and guilt. New York, NY: Guildford.

Tangney, J. P., Miller, R. S., Flicker, L., \& Barlow, D. H. (1996). Are shame, guilt, and embarrassment distinct emotions? Journal of Personality and Social Psychology, 70, $1256-1269$.

Tangney, J. P., \& Salovey, P. (1999). Problematic social emotions: Shame, guilt, jealousy and envy. In R. M. Kowalski \& M. R. Leary (Eds), The social psychology of emotional and behavioral problems (pp. 167-196). Washington, DC: American Psychological Association.

Tangney, J. P., Stuewig, J., \& Mashek, D. J. (2007). Moral emotions and moral behavior. Annual Review of Psychology, 58, 345-372.

Tangney, J. P., Wagner, P. E., \& Gramzow, R. (1989). The test of self-conscious affect. Fairfax, VA: George Mason University.

Tangney, J. P., Wagner, P. E., \& Gramzow, R. (1992). Proneness to shame, proneness to guilt, and psychopathology. Journal of Abnormal Psychology, 101, 469-478.

Taub, A. V. (1996). Guilt and bereavement: A comparative study of parents who have lost children (Unpublished thesis). United States International University, San Diego, CA, USA.

Tennen, H., Affleck, G., \& Gershman, K. (1986). Self-blame among parents of infants with perinatal complications: The role of self-protective motives. Journal of Personality and Social Psychology, 50, 690-696.

Theut, S. K., Pederson, F. A., Zaslow, M. J., Cain, R. L., Rabinovich, B. A., \& Morihisa, J. M. (1989). Perinatal loss and parental bereavement. American Journal of Psychiatry, $146,635-639$.

Tilghman-Osborne, C., Felton, J. W., \& Ciesla, J. A. (2008). Relation of guilt, shame, behavioral and characterological self-blame to depressive symptoms in adolescents over time. Journal of Social and Clinical Psychology, 27, 809-842.

Tomita, T., \& Kitamura, T. (2002). Clinical and research measures of grief: A reconsideration. Comprehensive Psychiatry, 43, 95-102.

Tracy, J. L., \& Robins, R. W. (2006). Appraisal antecedents of shame and guilt: Support for a theoretical model. Personality and Social Psychology, 32, 1339-1351.

Weinberg, N. (1995). Does apologizing help? The role of self-blame and making amends in recovery from bereavement. Health and Social Work, 20, 294.

Wiginton, K., Rhea, D. J., \& Oomen, J. (2004). Using the anger response inventory to evaluate the effect of shame and guilt on interpersonal communication skills. American Journal of Health Education, 35, 152-157.

\section{Author Biographies}

Catherine Duncan, MSW, is a Clinical Social Worker specializing in grief and loss support.

Joanne Cacciatore studies traumatic death and grief in families and is an Associate Professor in the School of Social Work at Arizona State University. 